Copyright (C) 2020 University of Bucharest Printed in Romania. All rights reserved

ISSN print: $1224-5984$

ISSN online: $2248-3942$
Rom Biotechnol Lett. 2020; 25(6): 2156-2160

doi: $10.25083 / \mathrm{rbl} / 25.6 / 2156.2160$

Received for publication, March, 10, 2020

Accepted, May, 11, 2020

Original paper

\title{
Effects of simulated microgravity on the morphology of mouse embryonic fibroblasts (MEFs)
}

\author{
HOANG NGHIA SON ${ }^{1,3}$, HO NGUYEN QUYNH CHI ${ }^{1,3}$, LE NGOC PHUONG \\ THANH ${ }^{1}$, TRUONG THI HAN ${ }^{1}$, NGUYEN THAI MINH HAN ${ }^{2}$, DOAN CHINH \\ CHUNG $^{1,3}$, LE THANH LONG ${ }^{1,3}$,*
}

${ }^{1}$ Institute of Tropical Biology, Vietnam Academy of Science and Technology

${ }^{2}$ Umeå Plant Science Centre, Umeå University, Umeå, Sweden

${ }^{3}$ Graduate University of Science and Technology, Vietnam Academy of Science and Technology

\begin{abstract}
This study aimed to assess the effects of simulated microgravity on mouse embryonic fibroblast (MEF) morphology. The results showed that the area of MEFs under simulated microgravity was $7843.39 \pm 551.31 \mu \mathrm{m}^{2}$ which was lower than the control group $\left(9832.72 \pm 453.86 \mu \mathrm{m}^{2}\right)(\mathrm{p}<0.001)$. The nuclear area of MEFs under simulated microgravity $\left(290.76 \pm 4.58 \mu \mathrm{m}^{2}\right)$ and the control group $\left(296.8 \pm 4.58 \mu \mathrm{m}^{2}\right)$ did not statistically differ. In addition, the nuclear shape value of the MEFs under simulated microgravity and the control group did not statistically differ $(0.86 \pm 0.006$ vs. $0.87 \pm 0.003$, respectively). The nuclear intensity of MEFs under simulated microgravity $(19361 \pm 852)$ was higher than the control group $(16997 \pm 285)(\mathrm{P}<0.05)$. Moreover, the flow cytometry analysis indicated the reduced G0/G1 phase cell ratio and the increased S phase and G2/M phase cell ratio in MEFs under simulated microgravity. Simulated microgravity also induced a decrease in diameter of actin filament bundles of the MEFs under simulated microgravity $(1.61 \pm 0.33 \mu \mathrm{m})$ compared to the control group $(1.79 \pm 0.32 \mu \mathrm{m})(\mathrm{P}<0.01)$. These results revealed that simulated microgravity is capable of inducing the morphological changes of mouse embryonic fibroblasts.
\end{abstract}

Keywords Cell morphology, actin filament, mouse embryonic fibroblast, simulated microgravity.

To cite this article: SON HN, CHI HNQ, THANH LNP, HAN TT, HAN NTM, CHUNG DC, LONG LT. Effects of simulated microgravity on the morphology of mouse embryonic fibroblasts (MEFs). Rom Biotechnol Lett. 2020; 25(6): 2156-2160. DOI: 10.25083/rb1/25.6/2156.2160

*Corresponding author: LE THANH LONG, Animal Biotechnology Department, Institute of Tropical Biology, Address: 9/621 Hanoi Highway, Linh Trung Ward, Thu Duc District, Ho Chi Minh City 700000, Vietnam, Phone number: (84) 365167243

E-mail: longlt@itb.ac.vn 


\section{Introduction}

Studies conducted in space have shown that biological properties are altered by gravity modification. Cells exposed to microgravity can be affected by changes of the physical conditions that occur in their environment, resulting in the loss of gravity-dependent molecular groups. Earth's gravity has the profound effect on cell adhesion and cellular matrix as well as the connection between cells (FREED, 1997). The impact on gravity leads to significant changes in the contractile apparatus of the cell in response to physiological stress and environmental conditions (KLEIN-NULEND, 2003). Changes in enzyme activity, genetics and epigenetics lead to many changes in tissue shape, cell function and cell activity (MONICI, 2006; MONTGOMERY, 1978). The absence of gravity reduces the biological function, which is contrary to the previous idea that the cells are not affected by the zero-gravity factor (TAIRBEKOV, 1983). Previous studies have shown that simulated microgravity affects cell shape and structure such as altering the flexibility and restructuring of actin filaments in mouse mesenchymal stem cells, or inducing the process of endothelial cell bone rearrangement by altering the expression of gelsolin and $\alpha$-tubulin (MAO, 2016; GRIFFONI, 2011). In this study, a microgravity model of 3D clinostat was used to assess the effects of simulated microgravity on morphological characteristics of mouse embryonic fibroblasts (MEFs) such as nuclear and cell area, actin filament structure, and the intensity of cell nucleus.

\section{Materials and Methods}

\section{MEF cell isolation and culture}

The mice fetus 12.5-13.5 dpc (days post coitum) was used for MEF isolation after removal of the uterus, amniotic fluid and placenta. The remainder of mice carcass was minced and incubated with $1 \mathrm{X}$ trypsinEDTA 15 minutes at $37^{\circ} \mathrm{C}$. The single cells were collected and transferred to flask containing $5 \mathrm{ml}$ of DMEM-F12 medium supplemented $10 \%$ FBS and $1 \%$ Pen/Strep. MEFs were cultured at $37^{\circ} \mathrm{C}, 5 \% \mathrm{CO}_{2}$. In order to induce the simulated microgravity condition, MEFs were seeded in 96-well plate with a density of $2 \times 10^{3}$ cells/well. After the cells adhered, $394 \mu \mathrm{l}$ of culture medium was added to each well. The parafilm membrane was used to cover the wells then the 96-well plate was placed in a 3D clinostat and induced in 72 hours. The simulated microgravity $\left(8 \times 10^{-3} \mathrm{G}\right)$ was generated by $3 \mathrm{D}$ clinostat with Mode $\mathrm{C}$ operation (Gravite ${ }^{\circledR}$, As One International, Inc., Santa Clara, CA 95054, USA).

\section{Staining of actin filament and nucleus}

After 3 days of culture under microgravity, the cells were washed twice with PBS solution, 5 minutes for each. The cells were then fixed with $4 \%$ paraformaldehyde solution for 30 minutes. Cells were washed twice with PBS solution. Cells were permeabilized with $0.1 \%$ Triton $\mathrm{X}-100$ and were incubated for 1 hour at room temperature. The cells were then washed twice with PBS solution. Actin filaments were stained with Phalloidin CruzLuor ${ }^{\mathrm{TM}} 488$ Conjugate, incubated for 1 hour at room temperature. The nucleus was stained with Hoechst $333422 \mu \mathrm{g} / \mathrm{ml}$ for 30 minutes. Cells were washed twice with PBS solution before observing under fluorescence microscope.

\section{Morphological analysis}

After staining of nucleus and actin filaments, the fluorescent images were taken using a Cytell fluorescence microscope. The Cell cycle App. of Cytell Microscope was used to analyze the nuclear area, nuclear intensity, and nuclear shape of MEFs. The images were further analyzed by Image $\mathbf{J}$ software (National Institutes of Health Bethesda, MD) to evaluate cell area and actin filament diameter. The color images were converted into an 8-bit color scale and adjusted to the same threshold for background removing. Cell area and diameter of actin bundle were consequently measured by Image $\mathbf{J}$ software (SON, 2019).

\section{Flow cytometry}

MEFs were cultured in T-25 flask with density of $1 \times 10^{5}$ cells/flask. The culture medium was applied to fill up the flask, then the flask was slowly capped to avoid bubbles. MEFs were induced the simulated microgravity for 72 hours. Cell cycle progression was estimated by flow cytometry using FITC Annexin V Apoptosis Detection Kit I (556547, BD Biosciences, United States).

\section{Analytical methods}

Data were analyzed and processed by Sigma Plot 11.0, with $\mathrm{P} \leq 0.05$ was evaluated as statistically significant.

\section{Results}

The flow cytometry was applied to evaluate the cell cycle progression of MEF. In control group, the ratio of $\mathrm{MEF}$ in G0/G1 phase was $88.93 \pm 0.32 \%$ (Figure 1A). The cell ratio in G0/G1 phase was reduced in MEF under simulated microgravity $(75.07 \pm 2.13 \%)$ (Figure $1 \mathrm{~B})$. The ratios in $\mathrm{S}$ phase and $\mathrm{G} 2 / \mathrm{M}$ phase of $\mathrm{MEF}$ from control group were $5.7 \pm 0.21 \%$ and $1.77 \pm 0.32 \%$, respectively. These ratios were increased in MEF under simulated microgravity $(8.83 \pm 0.69 \%$ in $\mathrm{S}$ phase and $11.97 \pm 1.75 \%$ in $\mathrm{G} 2 / \mathrm{M}$ phase). Moreover, cell density analysis demonstrated that the number of MEFs under simulated microgravity and control group was $2325 \pm 103$ and 2069 \pm 42 cells/well, respectively (Figure 1C). This suggested that simulated microgravity induced an increase of MEF proliferation.

Figure 2 showed that the simulated microgravity reduced the area of MEFs compared to the control group. The area of MEFs under simulated microgravity $\left(7843.39 \pm 551.31 \mu \mathrm{m}^{2}\right)$ was lower than the control group $\left(9832.72 \pm 453.86 \mu \mathrm{m}^{2}\right)(\mathrm{P}<0.001)$. The analysis of microfilament bundles size demonstrated that the diameter of microfilament bundles in MEFs under simulated microgravity was decreased, comparing to the control group. The diameter of microfilament bundles in simulated microgravity $(1.61 \pm 0.33 \mu \mathrm{m})$ was smaller than the control group $(1.79 \pm 0.32 \mu \mathrm{m})(\mathrm{P}<0.01)$ (Figure 2D). 


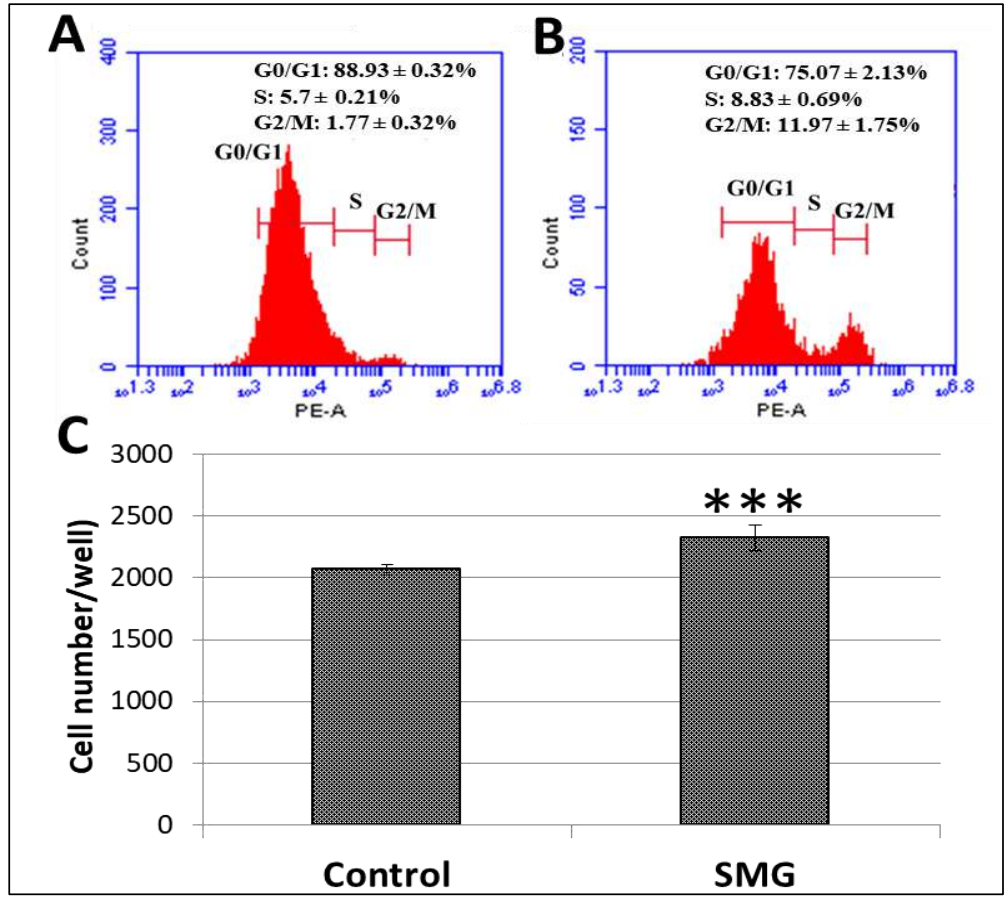

Figure 1. The cell cycle progression analysis. A. Cell cycle analysis by flow cytometry of MEFs from control group; B. Cell cycle analysis by flow cytometry of MEFs under simulated microgravity; C. MEF density analysis. $* * * \mathrm{P}<0.001$.

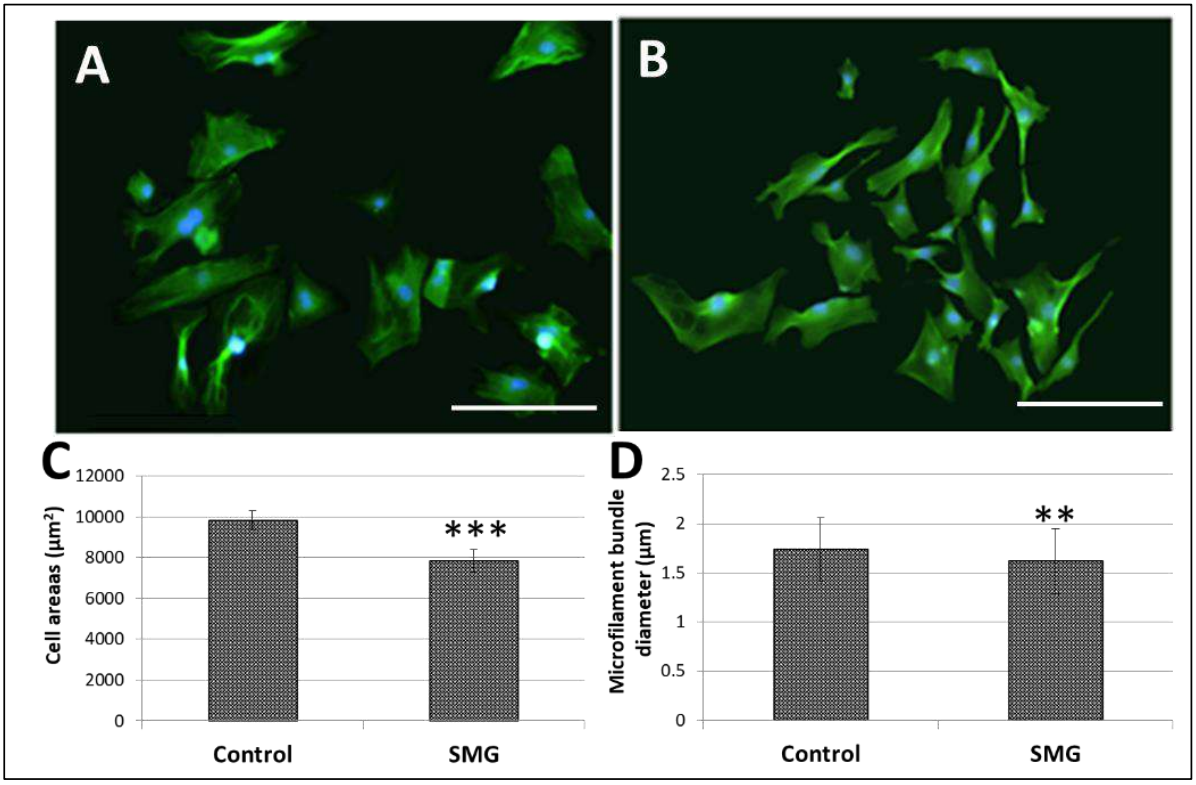

Figure 2. The changes of MEF area and microfilament bundles. $\mathbf{A}$ and B. MEFs in control group and simulated microgravity group. Microfilament was stained with Phalloidin (green color), the nuclear was counterstained with $\mathrm{H} 33342$ (blue); $\mathbf{C}$. The changes of MEF area; D. The changes of microfilament bundle diameter in MEFs. Scale bar is $223.64 \mu \mathrm{m}$. ***P $<0.001$.

The nuclear area of MEFs under simulated microgravity and in the control group was $290.76 \pm 4.58$ and $296.8 \pm 4.58 \mu \mathrm{m}^{2}$, respectively (Figure 3C). However, the difference was not statistically significant. This shows that the microgravity condition does not affect the change in the MEF nuclear area. The nuclei of normal cells are spherical, and the changes in the nuclear shape are related to the cell cycle and apoptosis which affects to the function of the cell. In this study, we assessed the change in MEF nuclear shape using Cytell software. The value of MEF nuclear shape under simulated microgravity and the control group was $0.86 \pm 0.006$ and $0.87 \pm 0.003$, respectively (Figure 3D). However, due to its unstatistical significant difference, the simulated microgravity 
showed no effect on MEF nuclear shape change.

The nuclear intensity of MEFs under simulated microgravity was higher than the control (Figure 4). The MEF nuclear intensity in simulated microgravity
$(19363 \pm 852)$ was 1.14 -fold higher than in the control group $(16997 \pm 285)(\mathrm{p}<0.05)$ (Figure $4 \mathrm{C})$. This result indicated that simulated microgravity could enhance the nuclear intensity of MEFs.

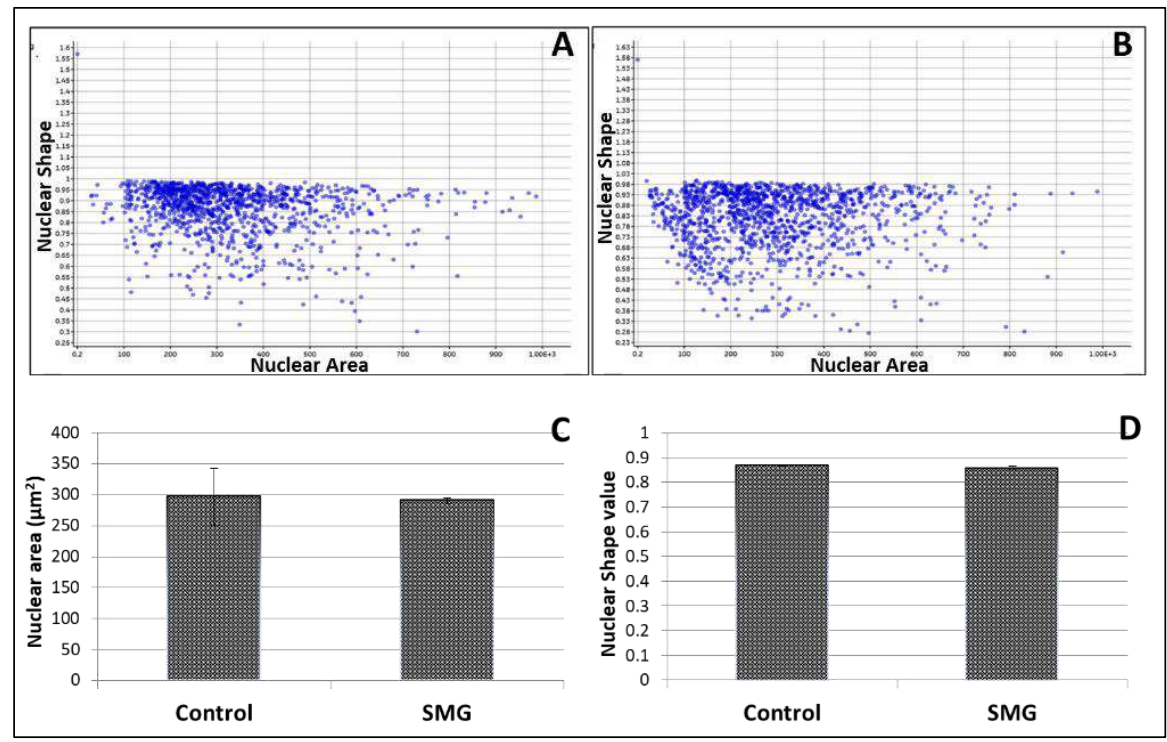

Figure 3. The changes in MEF nuclear area and nuclear shape. A and B. The graph shows the relationship of nuclear area and nuclear shape by Cytell software in the control cell group (A) and simulated microgravity $(\mathbf{B}) ; \mathbf{C}$. The changes of MEF nuclear area; $\mathbf{D}$. the changes of MEF nuclear shape.

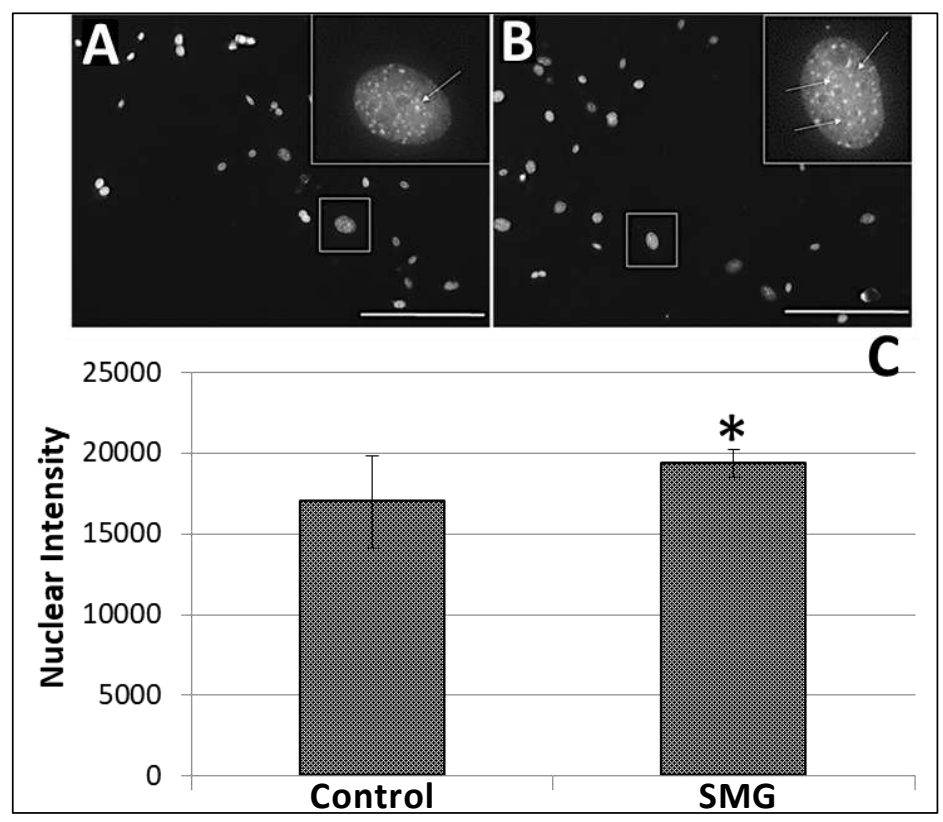

Figure 4. MEF nuclear intensity. The cell nuclei were stained with $\mathrm{H} 33342$ and analyzed by Cytell microscope; A. Control group; B. Simulated microgravity group; C. The changes of MEF nuclear intensity. Scale bar $223.64 \mu \mathrm{m} . * \mathrm{P}<0.05$.

\section{Discussion}

Gravity always affects all living things on Earth, the change of gravity leads to serious consequences for the 2005). The previous study reported that the size of cultured condition was also proven to rearrange actin filaments and cells under simulated microgravity conditions was smaller increased F-actin de-polymerization in HPMECs endothelial than cells under normal gravity (VASSY, 2001). In the addition, the actin filaments of 3T3 fibroblasts were rearranged in simulated microgravity, the actin was organized into microfiber and chaotic after 3 days of exposure to 
cell line (KANG, 2011). In this study, we found that microgravity conditions can alter the mechanical properties of mouse embryonic fibroblasts including the changes in the cytoskeleton structure and the changes in fibroblast morphology. Under simulated microgravity condition, MEFs became smaller in size which was resulted from the reduction of MEF area. This change could be caused by the modification of microfilament bundle structure, in which the decrease of actin diameter was observed in MEFs under simulated microgravity. This study results were consistent with above studies.

The nuclear reconstruction requires the synthesis of DNA and cellular components during the cell cycle. The nuclear size increases nearly twice in dividing cells at the interphase (WEBSTER, 2009; MAESHIMA, 2011). Moreover, the duplication of genomic DNA results in nuclear intensity enhancement and chromatin condensation which is a crucial process in mitosis (HABELA, 2007). In the present work, MEFs under simulated microgravity showed a higher nuclear intensity than control group, suggesting that number of dividing MEFs under simulated microgravity was higher than the control group. This was supported by the flow cytometry analysis, in which, the ratio of MEFs in G0/G1 phase was lower than control group. On the other hand, the MEF density under simulated microgravity was higher than control group. These results demonstrated that the simulated microgravity could induce the proliferation of MEFs.

The change in properties of MEFs can be attributed to the cytoskeletal rearrangement or a decrease in the content of actin filament. Research by Francesca Cialdai et al. showed that actin organized into small and chaotic fibers after 3 days of microgravity exposure (CIALDAI, 2017). Therefore, it could be considered that the cytoskeleton may be sensitive to changes in microgravity, which can lead to changes in cell morphology. In this work, the changes were determined in MEF area, MEF nuclear intensity, and microfilament bundles. However, the nuclear shape and the nuclear area did not change when being exposed to simulated microgravity, which may be due to the time being not long enough for the microgravity to change those characteristics.

\section{Conclusions}

In the present work, the proliferation of MEFs was increased in simulated microgravity condition. We also found that simulated microgravity could induce the morphological changes in MEFs by demonstrating the reduction of cellular area and diameter of microfilament bundles, or enhancement of nuclear intensity.

\section{Acknowledgements}

This study was supported by project VT-CB.15/18-20 of the National Aerospace Science and Technology Program from the Vietnam Academy of Science and Technology.

\section{References}

1. BIZZARRI M, MONICI M, VAN LOON JJWA. How Microgravity Affects the Biology of Living Systems. Biomed Res Int. 2015; 863075. doi: 10.1155/2015/863075

2. CIALDAI F, VIGNALI L, MORBIDELLI L, COLCIAGO A et al. Modeled Microgravity Affects Fibroblast Functions
Related to Wound Healing. Microgravity Sci Technol. 2017; 29: 121-132. doi: 10.1007/s12217-016-9532-7

3. FREED LE, LANGER R, MARTIN I, PELLIS NR et al. Tissue engineering of cartilage in space. Proc Natl Acad Sci USA. 1997; 94(25): 13885-13890. doi: 10.1073/pnas.94.25. 13885

4. GRIFFONI C, DI MOLFETTA S, FANTOZZI L, ZANETTI $\mathrm{C}$ et al. Modification of proteins secreted by endothelial cells during modeled low gravity exposure. J Cell Biochem. 2011; 112(1): 265-272. doi: 10.1002/jcb.22921

5. GRIMM D, WEHLAND M, PIETSCH J, ALESHCHEVA $\mathrm{G}$ et al. Growing tissues in real and simulated microgravity: new methods for tissue engineering. Tissue Eng Part B Rev. 2014; 20(6): 555-566. doi: 10.1089/ten.TEB.2013.0704

6. HABELA CW, SONTHEIMER H. Cytoplasmic volume condensation is an integral part of mitosis. Cell Cycle. 2007; 6(13): 1613-1620. doi: 10.4161/cc.6.13.4357

7. HÄDER PD, HEMMERSBACH R, LEBERT M. Gravity and the behavior of unicellular organisms (Developmental and Cell Biology Series). Cambridge: Cambridge University Press. 2005. doi: 10.1017/CBO9780511546211

8. KANG CY, ZOU L, YUAN M, WANG Y et al. Impact of simulated microgravity on microvascular endothelial cell apoptosis. Eur J Appl Physiol. 2011; 111(9): 2131-2138. doi: 10.1007/s00421-011-1844-0

9. KLEIN-NULEND J, BACABAC RG, VELDHUIJZEN JP, VAN LOON JJ. Microgravity and bone cell mechanosensitivity. Adv Space Res. 2003; 32(8): 1551-9. doi: 10.1016/S0273-1177(03)90395-4

10. MAESHIMA K, IINO H, HIHARA S, IMAMOTO N. Nuclear size, nuclear pore number and cell cycle. Nucleus. 2011; 2(2): 113-118. doi:10.4161/nucl.2.2.15446

11. MAO X, CHEN Z, LUO Q, ZHANG B et al. Simulated microgravity inhibits the migration of mesenchymal stem cells by remodeling actin cytoskeleton and increasing cell stiffness. Cytotechnology. 2016; 68(6): 2235-2243. doi: 10.1007/s10616-016-0007-x

12. MONICI M, FUSI F, PAGLIERANI M, MARZILIANO N et al. Modeled gravitational unloading triggers differentiation and apoptosis in preosteoclastic cells. $J$ Cell Biochem. 2006; 98(1): 65-80. doi: 10.1002/jcb.20747

13. MONTGOMERY PO JR, COOK JE, REYNOLDS RC, PAUL JS et al. The response of single human cells to zero gravity. In Vitro. 1978; 14(2): 165-73. doi: 10.1007/bf02618218

14. SON HN, CHI HNQ, CHUNG DC, LONG LT. Morphological changes during replicative senescence in bovine ovarian granulosa cells. Cell Cycle. 2019; 18(13): 14901497. doi: 10.1080/15384101.2019.1624108

15. TAIRBEKOV MG, PARFYONOV GP, SHEPELEV EYA, SUSHKOV FV. Experimental and theoretical analysis of the influence of gravity at the cellular level: a review. $A d v$ Space Res. 1983; 3(9): 153-158. doi: 10.1016/02731177(83)90052-2

16. VASSY J, PORTET S, BEIL M, MILlOT G et al. The effect of weightlessness on cytoskeleton architecture and proliferation of human breast cancer cell line MCF-7. FASEB J. 2001; 15(6): 1104-1106. doi: 10.1096/fj.00-0527fje

17. WEBSTER M, WITKIN KL, COHEN-FIX O. Sizing up the nucleus: nuclear shape, size and nuclear-envelope assembly. J Cell Sci. 2009; 122(10): 1477-1486. doi: 10.1242/jcs.037333 